\title{
Dynamics of the $\boldsymbol{\beta}_{2}$-adrenergic G-protein coupled receptor revealed by hydrogen-deuterium exchange
}

\author{
Xi Zhang ${ }^{1}$, Ellen Y.T. Chien ${ }^{2}$, Michael J. Chalmers ${ }^{1}$, Bruce D. Pascal ${ }^{1}$, Jovylyn Gatchalian², \\ Raymond C. Stevens ${ }^{2}$, and Patrick R. Griffin ${ }^{1}$ \\ ${ }^{1}$ Department of Molecular Therapeutics, The Scripps Research Institute, Jupiter, FL 33458 \\ 2 Department of Molecular Biology, The Scripps Research Institute, La Jolla, CA 92037
}

\begin{abstract}
To examine the molecular details of ligand activation of G-protein coupled receptor (GPCRs), emphasis has been placed on structure determination of these receptors with stabilizing ligands. Here we present the methodology for receptor dynamics characterization of the GPCR human $\beta_{2}$ adrenergic receptor bound to the inverse agonist carazolol using the technique of amide hydrogen/ deuterium exchange coupled with mass spectrometry (HDX MS). The HDX MS profile of receptor bound to carazolol is consistent with thermal parameter observations in the crystal structure and provides additional information in highly dynamic regions of the receptor and chemical modifications demonstrating the highly complementary nature of the techniques. Following optimization of HDX experimental conditions for this membrane protein, better than $89 \%$ sequence coverage was obtained for the receptor. The methodology presented paves the way for future analysis of $\beta_{2} \mathrm{AR}$ bound to pharmacologically distinct ligands as well as analysis of other GPCR family members.
\end{abstract}

\section{Keywords}

$\beta_{2}$-adrenergic receptor; G-protein coupled receptor; H/D exchange; mass spectrometry; membrane proteins

\section{Introduction}

G-protein coupled receptors (GPCRs) are molecular targets of many therapeutic drugs used in the treatment of a wide range of disorders and diseases ${ }^{1-} 3$. The prototypic GPCR $\beta_{2}$-adrenergic receptor $\left(\beta_{2} \mathrm{AR}\right)$ plays a critical role in converting external stimuli into intracellular signals that regulate many cellular processes. $\beta_{2} \mathrm{AR}$ is expressed predominantly in smooth muscle, skeletal muscle and liver and has been shown to be involved in regulation of muscle relaxation, glycogenolysis, gluconeogenesis and potassium uptake ${ }^{4}$. Drugs that modulate $\beta_{2} \mathrm{AR}$ have been developed to treat diseases such as asthma ${ }^{1,5}$. Typical of members of the GPCR superfamily, human $\beta_{2}$ AR contains 413 amino acids composed of seven transmembrane helices, an extracellular $\mathrm{N}$-terminus, and an intracellular $\mathrm{C}$-terminus $1^{-3}$. The receptor is activated upon binding of endogenous (catecholamines) or synthetic ligands that modulate receptor-G-protein interaction. Specifically, in the resting state, $\beta_{2} \mathrm{AR}$ associates with G-protein via its intracellular $3^{\text {rd }}$ loop and C-terminus and upon ligand binding, conformational changes likely facilitate the release of G-protein subunits that initiate a subsequent signaling cascade ${ }^{4}$. Understanding the structure and conformational dynamics of $\beta_{2} \mathrm{AR}$ is essential to understanding the mechanism

*Address reprints request to: Patrick R. Griffin, PhD, The Scripps Research Institute, Scripps Florida, 130 Scripps Way \#2A2, Jupiter, FL 33458, Phone (561) 228-2200, Fax (561) 228-3081, pgriffin@ scripps.edu. 
of action of natural and synthetic ligands. This structural information will aid in the design and development of functionally selective GPCR modulators.

Recent successes in high resolution x-ray crystallography have revealed the structures of human $\beta_{2} \mathrm{AR}$ in the inverse agonist or inactive form ${ }^{6-8}$. These high resolution structures were obtained for the ligand bound form with the insertion of T4-lysozyme domain replacing a highly dynamic third intracellular loop ${ }^{6-8}$. While these inactive structures provided significant insight into the structure of GPCRs as well as the molecular details of ligand interaction, questions remain about conformational dynamics, active state structure, and the role of dynamic regions of the receptor. For instance, the $\mathrm{N}$ - and $\mathrm{C}$-termini of the receptor, which are subjected to extensive post-translational modifications and are expected to play critical roles in the interaction with signaling molecules, remain largely unresolved by crystallography ${ }^{6-8}$. Most proteins are globular in nature and are dynamic molecules that undergo constant flexing and motion. Changes in protein conformation and dynamics are important to molecular recognition and these changes occur during many key biological processes such as ligand binding to receptors. Thus, techniques to study protein structure and dynamics are critical to the understanding of biological processes.

Amide hydrogen/deuterium exchange (HDX) can be used to probe protein dynamics, and is an ideal complement to other structural techniques such as x-ray crystallography ${ }^{9}, 10$. HDX has increasingly demonstrated its exceptional capability to study the fine dynamic structural changes of large complicated protein systems 11,12 . The exchange rate of an amide hydrogen is influenced significantly by hydrogen bonding and exchange kinetics of an amide hydrogen can be highly reflective of its locations in secondary and tertiary structures 10,13 . The methods of choice for measuring solution phase HDX are nuclear magnetic resonance (NMR) and mass spectrometry ${ }^{14,15}$. While NMR offers single amide resolution the technique requires large amounts of protein and the analysis can be limited to relatively small proteins. The coupling of HDX with mass spectrometry affords high sensitivity requiring very low amount of protein with virtually no limit to size or complexity of the protein, and is tolerant of impurities.

However, to date, HDX studies have primarily focused on soluble proteins and reports on membrane proteins are very limited 16, 17 with no published comprehensive HDX studies of a GPCR. The lack of HDX reports on membrane proteins is likely due to the technical challenges of analysis of membrane proteins.

HDX MS involves proteolytic digestion of the target protein with acid stable proteases under so called "slow exchange" conditions (low $\mathrm{pH}$ and low temperature) to minimize loss of deuterium during digestion and subsequent mass analysis. Unfortunately, like all GPCRs, $\beta_{2} \mathrm{AR}$ contains seven highly hydrophobic transmembrane helices, is very sensitive to $\mathrm{pH}$, and is prone to aggregation in detergent solubilized solution. 18 These structural features limit accessibility of protease leading to low digestion efficiency in aqueous solution conditions optimized for HDX studies. Further limiting digestion efficiency under HDX conditions are short digestion times and use of immobilized protease columns. Purification procedures for isolating GPCRs require the presence of detergent to maintain native structure, solubility and functional activity 19 and purified GPCRs often have bound phospholipids, sterols and detergents $6^{-8}$. Problematic for HDX MS, many commonly used detergents can interfere with mass spectrometry analysis. Due to their highly polar or charged head groups, detergents can cause ion suppression during the electrospray ionization (ESI) or matrix-assisted laser desorption/ionization (MALDI) process, although non-ionic detergents have been shown to be the least detrimental ${ }^{20}$. The non-ionic detergent $n$-dodecyl- $\beta$-D-maltoside (dodecyl maltoside, DDM) has been found to be applicable to most membrane proteins, not only in efficient solubilization and maintaining activity, but also in crystallization ${ }^{19}, 21^{-} 23$. To further complicate HDX MS analysis GPCRs such as $\beta_{2} \mathrm{AR}$ are potentially heavily post-translational 
modified with glycosylation, cysteine palmitoylation, phosphorylation, disulfide bonds, and ubiquitination $8,24-26$.

Through careful optimization of a wide range of experimental variables, significantly improved digestion efficiency can be obtained under HDX compatible conditions resulting in excellent sequence coverage. These optimized conditions enabled comprehensive HDX analysis of $\beta_{2} \mathrm{AR}$ bound to the inverse agonist carazolol. This study provides insights into structural dynamics of $\beta_{2} \mathrm{AR}$ and paves the way for comparative HDX studies of $\beta_{2} \mathrm{AR}$ bound with various functional ligands as well as HDX studies of other GPCRs.

\section{Experimental Section}

\section{Reagents and chemicals}

HPLC grade $\mathrm{H}_{2} \mathrm{O}, \mathrm{D}_{2} \mathrm{O}(99.9 \%)$, acetonitrile, formic acid, iso-propanol, tris-(carboxyethyl)phosphine hydrochloride (TCEP), iodoacetamide, Tris, $\mathrm{NaCl}, \mathrm{NaH}_{2} \mathrm{PO}_{4}$, glycerol and antiFLAG antibody, and horse heart myoglobin were purchased from Sigma-Aldrich (St. Louis, MO). Trifluoroacetic acid (TFA, Sequanal grade) was obtained from Pierce (Rockford, IL). High purity $n$-dodecyl- $\beta$-D-maltoside (DDM) and cholesterol hemisuccinate (CHS) were purchased from Anatrace Inc. (Maumee, OH). PNGase F at 500,000 unit/mL was purchased from New England BioLabs Inc. (Ipswich, MA). The pre-prepared 4-20\% tris-glycine gels used in sodium dodecyl sulfate polyacrylamide gel electrophoresis (SDS-PAGE) for Coomassie stain and Western blot were purchased from Invitrogen (Carlsbad, CA). The porcine pepsin-immobilized POROS 20 AL beads (particle size $20 \mu \mathrm{m}$ ) used to pack immobilized pepsin columns were purchased from Applied Biosystems (Foster City, CA).

\section{Expression and purification of $\beta_{2} A R$}

Human $\beta_{2} \mathrm{AR}$ containing an N-terminal FLAG tag and a C-terminal $10 \times$ His tag with E122W and N187E mutations (E130W and N195E in the current sequence shown in Figure S1 due to the 8-residue N-terminal FLAG) 8 and shortened 3IL and C-terminus (amino acid \#245-259 and 349-413 were deleted) was expressed in Sf9 insect cells and purified by using immobilized metal affinity chromatography (IMAC) with $50 \mu \mathrm{M}$ carazolol present. The protein was treated with $1 \mathrm{mg} / \mathrm{mL}$ iodoacetamide prior to solubilization to block the solvent-exposed free cysteine residues ${ }^{8}$. The final purified protein (typically $40-50 \mu \mathrm{M}$ ) with carazolol-bound and was kept in the buffer containing $50 \mathrm{mM}$ Hepes (pH 7.5), $150 \mathrm{mM} \mathrm{NaCl}, 10 \%$ (v/v) glycerol, $0.05 \%$ $(\mathrm{m} / \mathrm{v})$ DDM, $0.01 \%(\mathrm{~m} / \mathrm{v}) \mathrm{CHS}$ and $50 \mu \mathrm{M}$ carazolol. The protein concentration was determined with the bicinchroninic acid $\left(\mathrm{BCA}^{\mathrm{TM}}\right)$ protein assay kit (Pierce, Rockford, IL) using bovine serum albumin as a reference. Purity of the protein sample was followed using SDS-PAGE and analytical size exclusion chromatography. All sequence numbers cited in the current study referred to the $\beta_{2} \mathrm{AR}$ wild type sequence number shown in Figure $\mathrm{S} 1$.

\section{Sequence coverage of $\beta_{2} A R$}

Unless specified otherwise, the purified protein was diluted to $15 \mu \mathrm{M}$ for mass spectrometry experiments using the buffer composed of $50 \mathrm{mM}$ Hepes ( $\mathrm{pH} 7.5$ ), $150 \mathrm{mM} \mathrm{NaCl}, 2 \%$ (v/v) glycerol, $0.02 \%(\mathrm{~m} / \mathrm{v})$ DDM ( 3.3 critical micelle concentration $(\mathrm{cmc})), 0.01 \%(\mathrm{~m} / \mathrm{v}) \mathrm{CHS}$, and $\mathrm{H}_{2} \mathrm{O}$. The buffer for HDX on-exchange studies was the same composition except $\mathrm{H}_{2} \mathrm{O}$ was replaced with $\mathrm{D}_{2} \mathrm{O}(99.9 \%)$. Four $\mu \mathrm{L}$ of $\beta_{2} \mathrm{AR}$ protein was mixed by an automated system (described elsewhere 12) with $16 \mu \mathrm{L}$ of the $\mathrm{H}_{2} \mathrm{O}$ buffer and then $30 \mu \mathrm{L}$ of quench solution containing a number of different compositions (all at final $\mathrm{pH}$ of 2.2-2.5 prior to pepsin digestion), and digested either online by passing through an immobilized pepsin-coupled column $(2 \mathrm{~mm}$ i.d. $\times 20 \mathrm{~mm})$, or offline by incubation with pepsin-coupled bead slurry under room temperature $\left(27.8 \pm 0.5^{\circ} \mathrm{C}\right.$ at the bench). The digest was then separated by a Agilent (Santa Clara, CA) high-performance liquid chromatography (HPLC) equipped with a C8 trap (2 mm 
i.d., Thermo Fisher Scientific, San Jose, CA $)$ and C4 column $(2 \mathrm{~mm}$ i.d. $\times 50 \mathrm{~mm}$, Thermo Fisher Scientific, San Jose, CA) using a gradient of $45 \mathrm{~min}$, which started with 5\% B and linearly increased to $100 \% \mathrm{~B}$ over the next 45 minutes, unless specified otherwise. The mobile phase for the online immobilized pepsin-coupled column is $\mathrm{H}_{2} \mathrm{O}$ with $0.1 \%(\mathrm{v} / \mathrm{v})$ TFA and the flow rate is 50 or $200 \mu \mathrm{L} / \mathrm{min}$. For HPLC, buffer A is $\mathrm{H}_{2} \mathrm{O}$ containing $0.3 \%$ (v/v) formic acid, buffer B is acetonitrile: water at 4:1 (v/v) containing $0.3 \%(\mathrm{v} / \mathrm{v})$ formic acid, and flow rate is 50 or $200 \mu \mathrm{L} / \mathrm{min}$. The ESI MS and collision-induced dissociation (CID) tandem mass spectrometry (MS/MS) spectra of the peptides eluted from HPLC were acquired in positive ion mode on a quadrupole linear ion trap mass spectrometer equipped with an ESI source (Thermo Fisher Scientific, San Jose, CA) at capillary temperature of $225^{\circ} \mathrm{C}$ and spray voltage of $3.5 \mathrm{kV}$. Mass spectra were acquired for $\mathrm{m} / \mathrm{z}$ 300-2000 using a maximum injection time of $75 \mathrm{~ms}$ and target value of $3 \mathrm{e} 4$. Tandem mass spectra were obtained using data-dependent acquisition with dynamic exclusion where the top five most abundant ions in each scan were selected and subjected to CID. MS/MS spectra were acquired under wide band activation at an activation $Q$ value of 0.25 , activation time of $30 \mathrm{~ms}$, normalized collision energy of 35 , isolation width of 2.0, target number of 1e4 and maximum injection time of $100 \mathrm{~ms}$ unless specified otherwise. Each scan was the average of 3 microscans under normal scan mode in both MS and MS/MS.

All MS/MS spectra were analyzed using the MASCOT program. Searches were run without protein modifications and with modifications such as carboxamidemethyl cysteine, methionine oxidation, phosphorylation, and deglycosylation. Results from all searches against multiple sets of MS/MS data were combined. Peptides included in the peptide set used for HDX had a MASCOT score of 20 or greater. The MS/MS MASCOT search was also performed against a decoy (reverse) sequence and ambiguous identifications were ruled out. The MS/MS spectra of all of the peptide ions from the MASCOT search were further manually inspected and only those verifiable are used in the coverage.

\section{HDX analysis of $\beta_{2} A R$}

For HDX MS experiments, four $\mu \mathrm{L}$ of $\beta_{2} \mathrm{AR}$ protein was mixed with $16 \mu \mathrm{L}$ of the $\mathrm{D}_{2} \mathrm{O}$ buffer (final $\mathrm{D}_{2} \mathrm{O}$ content was $80 \%$ ) and incubated at various time intervals at $4{ }^{\circ} \mathrm{C}$, before being added to $30 \mu \mathrm{L}$ of quench solution containing $15 \mathrm{mM} \mathrm{TCEP}, 0.1 \mathrm{M} \mathrm{NaH}_{2} \mathrm{PO}_{4}(\mathrm{HCl}, \mathrm{pH} 2.4)$ and $0.02 \%$ $(\mathrm{m} / \mathrm{v})$ DDM. Deuterated protein was then digested online using the same procedure described above. HPLC (Eksigent, Dublin CA) was performed with a 9.5 min gradient at flow rate of 50 $\mu \mathrm{L} / \mathrm{min}$, and all of the pepsin column, trap and analytical columns applied to HDX-MS experiments were the same as in the MS/MS experiments except that the internal diameters were all decreased to $1 \mathrm{~mm}$. The gradient started with $5 \% \mathrm{~B}$, increased to $15 \% \mathrm{~B}$ over $0.1 \mathrm{~min}$, increased to $50 \%$ B within $5.4 \mathrm{~min}$, then quickly ramped to $98 \%$ within $0.5 \mathrm{~min}$, held for 1.5 $\mathrm{min}$, and dropped back to $5 \%$ within $0.1 \mathrm{~min}$. MS was acquired in the range of $\mathrm{m} / \mathrm{z} 300-2000$ for $8 \mathrm{~min}$ in positive ion mode on an orbi-trap mass spectrometer (Thermo Fisher Scientific, San Jose, CA) equipped with an ESI source operated at capillary temperature of $225^{\circ} \mathrm{C}$ and spray voltage of $3.5 \mathrm{kV}$. Protein and quench solutions, pepsin column, trap and HPLC columns were all kept at $1.0^{\circ} \mathrm{C}$ unless specified otherwise. HDX incubation was performed at $4.0^{\circ} \mathrm{C}$ for six different time points: 10 s, $30 \mathrm{~s}, 60 \mathrm{~s}, 300 \mathrm{~s}, 900 \mathrm{~s}$ and $3600 \mathrm{~s}$. The experiments were performed at random order, and between every two injections, blank injections were made to remove any potential protein carryover from previous runs. Two additional incubations $(12 \pm 1$ $\mathrm{hr}$ and $15 \mathrm{hr}$ ) were performed in $92 \% \mathrm{D}_{2} \mathrm{O}$ buffer in sealed centrifuge tubes also under $4^{\circ} \mathrm{C}$. The t0 data were acquired using the $\mathrm{H}_{2} \mathrm{O}$ buffer. Data for each on-exchange time point were obtained in four replicates (four individually prepared samples, not four injections of the same sample). 
All HDX data were normalized to $100 \% \mathrm{D}_{2} \mathrm{O}$ content ( $80 \% \mathrm{D}$ on-exchange buffer for the first 6 time points and $92 \%$ D on-exchange buffer for the $12 \pm 1 \mathrm{hr}$ and $15 \mathrm{hr}$ time points), corrected for an estimated average deuterium recovery of $70 \%$, and processed using the software HD Desktop ${ }^{27}$. Percent deuterium incorporation was plotted versus incubation time in log scale, and the date points were connected through a second order smoothing polynomial. All onexchange plots used in the analysis of $\beta_{2} A R$ are shown in Supplemental Figure S2. The HDX profile of carazolol-bound $\beta_{2} \mathrm{AR}$ was mapped to its own amino acid sequence and also to the crystal structure of human $\beta 2 \mathrm{AR}$ T4L monomer which is carazolol-bound and starts with W40 (PDB: 2RH1) ${ }^{8}$.

\section{De-glycosylation of $\beta_{2} A R$ through PNGase $F$ digestion}

The purified $\beta_{2} \mathrm{AR}$ was incubated with PNGase $\mathrm{F}$ at $4^{\circ} \mathrm{C}$ or $37^{\circ} \mathrm{C}$ for $1 \mathrm{hr}$ (PNGase $\mathrm{F}$ final concentration at $50 \mathrm{unit} / \mu \mathrm{L}$ ) prior to mass spectrometry experiments (MS/MS and HDX t0 MS). The effect of PNGase F digestion was monitored by SDS-PAGE and Western blot. HDX was performed on the protein following PNGase $\mathrm{F}$ treatment and separation using fast protein liquid chromatography (FPLC) at $4^{\circ} \mathrm{C}$.

\section{SDS-PAGE and western blot of $\beta_{2} A R$}

$\beta_{2}$ AR-460 proteins with and without PNGase $F$ treatment were mixed with NuPAGE LDS sample buffer, and loaded onto $10 \%$ Bis-Tris gels and stained with SimplyBue ${ }^{\mathrm{TM}}$ SafeStain (Invitrogen), or transferred to a membrane for Western blot using anti-FLAG antibody at 1:1000 (v:v) dilution.

\section{Results And Discussion}

\section{Optimization of protein sequence coverage - detergent, reductant, and HPLC parameters}

To obtain a comprehensive HDX profile of $\beta_{2} \mathrm{AR}$, procedures for analysis were progressively optimized directed by insights gained from crystal structure. Consideration was also made for putative posttranslational modifications, and considering the physical characteristics of membrane proteins. Our initial experiments used a quench solution of $3 \mathrm{M}$ urea and $1 \% \mathrm{TFA}$, however very limited sequence coverage was obtained for $\beta_{2} \mathrm{AR}(\sim 25 \%)$. In an effort to improve sequence coverage various experimental parameters were systematically optimized. Parameters optimized included protein concentration, various quench buffers (different combinations of denaturing and reducing reagents at various concentrations), temperature and length of digestion, HPLC conditions, MS acquisition settings (number of micro scans, max injection time), and the application of a static exclusion ion list including several recurrent low $\mathrm{m} / \mathrm{z}$ non-peptide ions for the MS/MS experiments (see Table 1).

During optimization of HDX experimental parameters, various protein concentrations were considered. As expected, $25 \mu \mathrm{M} \beta_{2} \mathrm{AR}$ afforded higher sequence coverage than $16 \mu \mathrm{M}$, indicating that the digestion efficiency is not limited by the digestion capacity of the pepsin column (Table 1). Using the typical HDX quench solutions composed primarily of high concentrations of urea and $1 \%(\mathrm{v} / \mathrm{v})$ TFA, 11,12 poor sequence coverage was obtained for all concentrations of urea tested ( $3 \mathrm{M}-8 \mathrm{M}$ ) with $4 \mathrm{M}$ urea providing the highest coverage. Also, without reductant, no peptides were observed from regions in proximity to the disulfide bonds. Although urea is usually considered to denature proteins making them more susceptible to proteases, the reagent was either not efficient at denaturing the membrane protein $\beta_{2} \mathrm{AR}$ or was unable to prevent aggregation at the low $\mathrm{pH}$ conditions of the digestion step ${ }^{28}$. Use of quench solutions composed of $0.1 \mathrm{M} \mathrm{NaH}_{2} \mathrm{PO}_{4}(\mathrm{pH} 2.4) / 0.02 \%$ DDM consistently afforded higher coverage than quench buffers containing urea. 
The crystal structure of $\beta_{2} \mathrm{AR}$ revealed two disulfide bonds in $\beta_{2} \mathrm{AR}$ (corresponding to C106$\mathrm{C} 191$ and $\mathrm{C} 184$ - C190 in $\beta_{2} \mathrm{AR}$ ) and palmitoylation of C341. Out of the total 11 cysteine residues, three cysteine residues (C77, C265 and C327) were determined to be present predominantly carboxamidomethylated as a result of prior iodoacetamide treatment (Supplemental Table S1). Peptides containing unmodified C265 and C327 were also detected but at low abundance. Consistent with the crystal structure, C265 was noted to be modified with an acetamide group in the electron density maps. These results suggested that these three cysteines are likely reduced and are readily accessible to the iodoacetamide treatment. Peptides containing cysteines that are involved in disulfide bonds will only be detected after exposure of protein to reductant. To improve coverage in proximity of disulfide bonds various reducing conditions were considered. The reductant TCEP has previously been applied in HDX studies to reduce disulfide bonds under acidic conditions and is typically used at high concentrations $(1 \mathrm{M}) .{ }^{11}, 29$ However, high concentrations of TCEP were shown here to yield poor peptide sequence coverage (Table 1). Upon investigation, high concentrations of TCEP (> $200 \mathrm{mM}$ ) resulted in mass spectra dominated by clusters of peaks formed by adducts of TCEP throughout most of the chromatographic gradient (data not shown) thus interfering with peptide identification. The interference results from overlapping ions, suppression of ionization, and filling the ion trap with chemical noise. In addition, the highly ionic nature of TCEP might have caused the membrane protein to aggregate or precipitate prior to peptic digestion. Although the sequence coverage was poor, the region of I182-F193 (INCYAEETCCDF) in the extracellular loop of $\beta_{2} \mathrm{AR}$, previously shown in crystal structures to contain one and a half disulfide bonds (C106 with C191, and C184 with C190) ${ }^{7}, 8$ was observed only when TCEP was used, confirming that this region is disulfide bonded in the protein construct used here. Upon further investigation of the $\beta_{2} \mathrm{AR}$ crystal structures (PDB: 3D4S and 2RH1) indicate that this region is in the solvent exposed extracellular loop (Figures 3 and S1), suggesting that perhaps low concentrations of TCEP might be sufficient to reduce this disulfide bond. Thus, addition of TCEP to the quench solution $\left(0.1 \mathrm{M} \mathrm{NaH}_{2} \mathrm{PO}_{4}(\mathrm{HCl}, \mathrm{pH} 2.40) 0.02 \%(\mathrm{~m} / \mathrm{v}) \mathrm{DDM}\right)$ was tested at various concentrations $(0,2,5,10,20,200$ and $500 \mathrm{mM})$. Results displayed in Table 1 demonstrate that incorporation of TCEP at concentrations as low as $5 \mathrm{mM}$ level is sufficient to reduce the disulfide bonds in $\beta_{2} \mathrm{AR}$ and as concentrations of TCEP reached 20 $\mathrm{mM}$, peptide sequence coverage started to decrease. Optimal TCEP concentration was determined to be in the range of $10-15 \mathrm{mM}$, and $15 \mathrm{mM}$ was used in the HDX studies presented here. Unfortunately, peptides containing C116 and C285 were not observed under all conditions employed.

The use of DDM at $0.02 \% \mathrm{~m} / \mathrm{v}(\sim 3 \mathrm{cmc})$ in quench solution consistently afforded improved sequence coverage under all conditions suggesting that keeping the membrane protein soluble and stable prior to and during digestion, is important to obtaining high sequence coverage. The use of DDM in the quench buffer may also aid the solubilization of extremely hydrophobic peptides generated during peptic digestion. Interestingly, DDM eluted near the end of the HPLC gradient as a single sharp peak, indicating its high purity, and resulted in minimal interference of $\beta_{2} \mathrm{AR}$ peptides. DDM formed predominantly protonated dimeric ions with minimal protonated monomer or cationic adduct formation observed. These results suggest that, in contrast to protease digestion of soluble proteins, digestion of highly hydrophobic membrane proteins requires careful maintenance of protein solubility in addition to efficient denaturation. While denaturation involves alteration of the protein tertiary structure, partial or complete protein aggregation may occur resulting in poor digestion efficiency by limiting the access of the protease to cleavage sites.

Several mass-spectrometry-compatible detergents that involve cleaving the detergent into smaller moieties prior to mass spectrometry analysis have recently been applied to improving protein analysis ${ }^{30,31}$. However, some types of the cleavable detergents are ionic and have been shown to cause precipitation of purified membrane proteins. In addition, the time required 
to cleave these detergents introduces an undesirable time window for back exchange. Each membrane protein is unique, and its structure, stability and activity are highly sensitive to the properties of a detergent ${ }^{19}$. For structural studies including HDX, it is essential that the detergent used during purification and analysis does not alter the protein's structure and stability. The evidence that DDM, a detergent proven to maximally maintain the structure and activity of $\beta_{2} \mathrm{AR}^{6-8}$, can significantly improve the digestion efficiency without causing appreciable interference in the mass spectrometer, makes the use of cleavable detergents unnecessary for HDX studies of $\beta_{2} \mathrm{AR}$.

Effects of temperature and length of digestion time were optimized by comparing sequence coverage and deuterium retention. Briefly, online digestion using immobilized pepsin-coupled column at room temperature was compared to offline digestion using pepsin-coupled beads slurry at $37^{\circ} \mathrm{C}$ for $30 \mathrm{~min}$, and online digestion at $1{ }^{\circ} \mathrm{C}$ and room temperature $\left(27^{\circ} \mathrm{C}\right)$ using t0 MS (Table 1). Not unexpectedly, these results demonstrate that digestion for longer time at higher temperature yield higher sequence coverage (offline $37{ }^{\circ} \mathrm{C}$ for $30 \mathrm{~min}$ vs. online at room temperature for less than one minute). However, it is important to note that these digestion conditions had minimal impact on deuterium retention. Using myoglobin as a control, no appreciable difference in deuterium recovery was observed when the pepsin-coupled column was held at $1^{\circ} \mathrm{C}$ or $22^{\circ} \mathrm{C}$.

Both a $\mathrm{C} 4$ and a $\mathrm{C} 8$ analytical columns were chosen in conjunction with a $\mathrm{C} 8$ trap column to ensure the recovery of the hydrophobic components within the gradient used for $\mathrm{HDX}^{32}$. Using the C8 trap column and C4 or C8 column, peptides were eluted within the 9.5 min HPLC gradient. Importantly, under these conditions DDM eluted as a narrow well defined peak just prior to the end of the gradient. In addition, intact diacylglycerolphospholipids isolated along with $\beta_{2}$ AR eluted after the DDM peak. Nearly all of the peptides are each found only at a single retention time range, suggesting that aggregation of protein or peptide in the eluted solution was minimal. This suggested that inclusion of detergents in the HPLC mobile phase is not required.

In initial MS/MS analysis of $\beta_{2} \mathrm{AR}$ under HDX conditions, sequence coverage of helix 1 and helix 3 was minimal. These regions of the protein are very hydrophobic and contain multiple pepsin cleavage sites ${ }^{33}$, suggesting that under HDX conditions, this region would only be represented by several small hydrophobic peptides. In addition to pepsin treatment, other acid stable proteases (fungal XIII and XVIII) were tested but failed to improve sequence coverage in this region. Thus, in an effort to improve detection of these peptides, the MS/MS experiment was run with an extended 120 min gradient. This method improved sequence coverage to $89 \%$ (Figure 2). Changing the MS/MS selection from top five ions to top 12 ions during the 120 min gradient did not result in any further improvement in sequence coverage, suggesting that the extended gradient afforded efficient separation of the peptic peptides.

\section{Optimization of protein sequence coverage - mass spectrometer settings}

Application of a precursor ion reject list containing five recurrent abundant precursor ions in data-dependent acquisition improved the coverage of identified peptides (Table 1). Blocking these abundant non-peptide ions allowed the less abundant peptide ions to be selected for MS/ MS analysis. The reject list was applied in addition to the dynamic exclusion. Increasing the maximum ion injection time for MS/MS experiments while keeping the target number unchanged can potentially enhance the fragment ion abundance in MS/MS spectrum by allowing the precursor ions more time to fill the trap to reach the target number before they are fragmented and scanned out to the detector. However, increasing the maximum injection time for MS/MS acquisition from $100 \mathrm{~ms}$ to $200 \mathrm{~ms}$ did not improve sequence coverage, suggesting that failing to identify peptides from the uncovered sequence is not due to their low fragmentation efficiency or low precursor ion abundance. Peptides not observed were either 
not formed efficiently during digestion and or their abundance was not sufficient to trigger MS/MS. It is also possible that the peptides are formed but cannot be trapped with the HPLC columns and chromatography conditions employed here. The combined optimal HDX experimental conditions were determined to be use of quench buffer of $0.1 \mathrm{M} \mathrm{NaH}_{2} \mathrm{PO}_{4}(\mathrm{HCl}$, $\mathrm{pH} 2.40) 0.02 \%(\mathrm{~m} / \mathrm{v}) \mathrm{DDM}$, offline digestion at $37^{\circ} \mathrm{C}$ for $30 \mathrm{~min}$ of $25 \mu \mathrm{M} \beta_{2} \mathrm{AR}$.

\section{Optimization of protein sequence coverage - protein modifications}

Based on the homology with other seven transmembrane-helix GPCRs, ${ }^{26,32,34}$ glycosylation and phosphorylation of the $\mathrm{N}$-terminus of $\beta_{2} \mathrm{AR}$ was expected. These modifications have been reported in human $\beta_{2} \mathrm{AR}$ using biochemical and proteomic approaches, and the phosphorylation was found to be regulated by ligand binding ${ }^{25}$. Initial MS/MS studies of $\beta_{2}$ AR failed to detect peptic peptides from the $\mathrm{N}$-terminus and transmembrane helix 1 , even though this region of the protein is extracellular and should be accessible to protease. As this region of the protein contains two putative glycosylation sites, N6 and N15 25, 26, 32, 34, 35, the protein was treated with $\mathrm{PNGase} \mathrm{F}$ to remove $\mathrm{N}$-glycosylation of asparagines. Western blot analysis of $\beta_{2} \mathrm{AR}$ following $1 \mathrm{hr}$ of PNGase $\mathrm{F}$ treatment (Figure 1) clearly demonstrates effective removal of sugars. No difference was observed between the $4^{\circ} \mathrm{C}$ and $37^{\circ} \mathrm{C}$ treatments. MS/MS analysis of $\beta_{2} \mathrm{AR}$ following PNGase $\mathrm{F}$ treatment lead to the identification of peptides originating from the $\mathrm{N}$-terminus (residues 1-19), confirming that $\beta_{2} \mathrm{AR}$ was heavily glycosylated.

Further posttranslational modifications were considered in an effort to improve sequence coverage. Analysis of the crystal structure of $\beta_{2} \mathrm{AR}$ shows that C334 is palmitoylated. However, in all MS and MS/MS runs under HDX conditions no peptic peptides were detected that corresponded to C334 as either unmodified or palmitoylated even though the palmitoyl group was observed in the crystal structure. Thus, this region of the receptor was undetected in the HDX experiments described below. Lastly, $\beta_{2}$ AR contains several phosphorylation sites ${ }^{25}$ although the $\beta_{2} \mathrm{AR}$ protein material made in sf 9 cells are not expected to be phosphorylated under the existing conditions. MASCOT analysis of all MS/MS spectra confirmed the absence of phosphorylated residues. Finally, MASCOT analysis of all MS/MS spectra where methionine was considered as sulfoxide or sulfone did not result in an improvement of $\beta_{2} \mathrm{AR}$ sequence coverage, suggesting that the methionine oxidation is minimal.

\section{HDX profile of $\beta_{2} A R$ bound to carazolol}

To visualize the dynamics of $\beta_{2} \mathrm{AR}$, HDX data obtained at $30 \mathrm{~s}, 300 \mathrm{~s}$ and $15 \mathrm{~h}$ were overlaid onto a structure model derived from the crystal structure of $\beta_{2} \mathrm{AR}$ T4L bound to carazolol (PDB: 2RH1) as shown in Figure 3. The structure model was derived from PDB: 2RH1 with removal of T4L amino acids to reflect the construct used for HDX studies. All non-protein molecules were removed with the exception of bound carazolol. A comprehensive HDX profile of carazolol-bound $\beta_{2} \mathrm{AR}$ is presented in Figure 4A. Deuterium incorporation versus time (log scale) for several representative peptides are shown in Figure 4B (see Figure S2 for all plots). As illustrated in Figure 3A, significant protection to exchange was observed for all transmembrane helices throughout the entire time course monitored $(15 \mathrm{~h})$. The highest degree of protection to exchange was detected toward the core of these helices, while the linkages between helices displayed moderate exchange kinetics. Peptides representative of the third cytoplasmic loop at the C-terminus of helix 5 ( $3^{\text {rd }}$ intracellular loop) demonstrated the most rapid exchange kinetics. This is the region of $\beta_{2} \mathrm{AR}$ that was replaced with $\mathrm{T} 4 \mathrm{~L}$ to facilitate crystallization and also the loop region known to interact with G-alpha. Peptides representative of the N-terminus of the receptor also exhibited rapid exchange kinetics. The short helical loop between helix 4 and helix 5 ( $2^{\text {nd }}$ extracellular domain) displayed an intermediate exchange rate that is faster than the transmembrane helices but slower than the intra-helical linkages. This observation is interesting since the rhodopsin $2^{\text {nd }}$ extracellular loop region covers the access 
to the retinal binding site in the rhodopsin structure where retinal undergoes a cis to trans isomerization instead of retinal coming on and off. ${ }^{36}$ In contrast to the $\beta_{2} \mathrm{AR}$ structure and the HDX data, the $3^{\text {rd }}$ extracellular loop that contains an ordered short helix may be a lid that is capable of moving over and away from the ligand binding site in different conformational states.

\section{Conclusions}

Previously we have described a robust HDX platform that provides comprehensive and reproducible analysis of proteins such as nuclear receptors, enzymes, and matrix metalloproteases ${ }^{12}$. Using this HDX platform we uncovered a novel mechanism for partial agonist activation of the nuclear receptor PPAR $\gamma$, unique binding modes of natural and synthetic estrogens on ER $\alpha$ and ER $\beta$, and substrate binding site on MMP1 ${ }^{12,} 37-40$. Here we demonstrate the ability to determine which regions of the integral membrane $\beta_{2}$-adrenergic Gprotein coupled receptor are more dynamic than other regions of the membrane protein. Although for membrane proteins, the regions of flexibility might seem obvious, the results presented here highlight a number of dynamic secondary elements being observed in relatively small extra- or intracellular loops indicating the functional importance of these regions. While analysis of $\beta_{2} \mathrm{AR}$ with previously optimized conditions resulted in less than ideal sequence coverage, optimization of several experimental parameters and by consideration of the sequence and structure of the receptor, sequence coverage of $\beta_{2} \mathrm{AR}$ was significantly improved while maintaining HDX compatible conditions. Following optimization, excellent sequence coverage was obtained spanning the entire $\beta_{2} \mathrm{AR}$ structure with few exceptions. Importantly, sequence coverage was obtained for regions that were unresolved in the crystal structures and these highly dynamic regions of the receptor are likely important to receptor function such as ligand recognition and receptor signaling. The improved methodology presented here enabled effective and comprehensive HDX characterization of human $\beta_{2} \mathrm{AR}$ bound to the inverse agonist carazolol. A great deal of insight on GPCR dynamics will come from differential HDX analysis of different ligands bound such as comparison of agonist, antagonists, and inverse agonists and observing the changes in dynamics relative to the varying functional states of the receptor. The methodology presented paves the way for future analysis of other GPCR family members.

\section{Supplementary Material}

Refer to Web version on PubMed Central for supplementary material.

\section{Acknowledgments}

The work is supported by GM084041 (X.Z., P.R.G., M.J.C., B.D.P) and NIH Roadmap Initiative grant P50 GM073197 (E.Y.T.C., R.C.S.).

\section{References}

1. Hanson MA, Stevens RC. Structure (Cambridge, MA, United States) 2009;17:8-14.

2. Kroeze WK, Sheffler DJ, Roth BL. Journal of Cell Science 2003;116:4867-4869. [PubMed: 14625380]

3. Conn PJ, Christopoulos A, Lindsley CW. Nature Reviews Drug Discovery 2009;8:41-54.

4. Golan, DE.; T, AH., Jr; Armstrong, EJ.; Armstrong, AW. Principles of pharmacology: The pathophysiologic Basis of Drug Therapy. 2nd. Lippincott Williams \& Wilkins; Baltimore, MD: 2008.

5. Penn RB. Proceedings of the National Academy of Sciences 2009;106:2095-2096.

6. Rosenbaum DM, Cherezov V, Hanson MA, Rasmussen SG, Thian FS, Kobilka TS, Choi HJ, Yao XJ, Weis WI, Stevens RC, Kobilka BK. Science 2007;318:1266-1273. [PubMed: 17962519] 
7. Cherezov V, Rosenbaum DM, Hanson MA, Rasmussen SG, Thian FS, Kobilka TS, Choi HJ, Kuhn P, Weis WI, Kobilka BK, Stevens RC. Science 2007;318:1258-1265. [PubMed: 17962520]

8. Hanson MA, Cherezov V, Griffith MT, Roth CB, Jaakola VP, Chien EYT, Velasquez J, Kuhn P, Stevens RC. Structure (Cambridge, MA, United States) 2008;16:897-905.

9. Englander SW. Journal of the American Society for Mass Spectrometry 2006;17:1481-1489. [PubMed: 16876429]

10. Katta V, Chait BT, Carr S. Rapid Commun Mass Spectrom 1991;5:214-217. [PubMed: 1666528]

11. Bruning JB, Chalmers MJ, Prasad S, Busby SA, Kamenecka TM, He Y, Nettles KW, Griffin PR. Structure (Cambridge, MA, United States) 2007;15:1258-1271.

12. Chalmers MJ, Busby SA, Pascal BD, He Y, Hendrickson CL, Marshall AG, Griffin PR. Analytical chemistry 2006;78:1005-1014. [PubMed: 16478090]

13. Cravello L, Lascoux D, Forest E. Rapid Commun Mass Spectrom 2003;17:2387-2393. [PubMed: 14587084]

14. Shimada I. Nuclear Magnetic Resonance of Biological Macromolecules, Part C 2005;394:483-+.

15. Engen JR, Smith DL. Anal Chem 2001;73:256A-265A.

16. Busenlehner LS, Salomonsson L, Brzezinski P, Armstrong RN. Proceedings of the National Academy of Sciences 2006;103:15398-15403.

17. Busenlehner LS, Branden G, Namslauer I, Brzezinski P, Armstrong RN. Biochemistry 2008;47:7383. [PubMed: 18052347]

18. White SH, Ladokhin AS, Jayasinghe S, Hristova K. Journal of Biological Chemistry 2001;276:3239532398. [PubMed: 11432876]

19. Garavito RM, Ferguson-Miller S. J Biol Chem 2001;276:32403-32406. [PubMed: 11432878]

20. Cristoni S, Bernardi LR. Mass Spectrom Rev 2003;22:369-406. [PubMed: 14528493]

21. Thompson DA, Suarez-Villafane M, Ferguson-Miller S. Biophys J 1982;37:285-293. [PubMed: 6275925]

22. le Maire M, Champeil P, Møller JV. Biochimica et Biophysica Acta, Biomembranes 2000;1508:86111.

23. Qin L, Hiser C, Mulichak A, Garavito RM, Ferguson-Miller S. Proc Natl Acad Sci U S A 2006;103:16117-16122. [PubMed: 17050688]

24. Marchese A, Benovic JL. Methods in Molecular Biology (Totowa, NJ, United States) 2004;259:299_ 305.

25. Trester-Zedlitz M, Burlingame A, Kobilka B, Von Zastrow M. Biochemistry 2005;44:6133-6143. [PubMed: 15835901]

26. Li J, Edwards PC, Burghammer M, Villa C, Schertler GFX. Journal of Molecular Biology 2004;343:1409-1438. [PubMed: 15491621]

27. Pascal BD, Chalmers MJ, Busby SA, Griffin PR. Journal of the American Society for Mass Spectrometry 2009;20:601-610. [PubMed: 19135386]

28. Lim WK, RÃ $\llbracket$ sgen Jr, Englander SW. Proceedings of the National Academy of Sciences 2009;106:2595-2600.

29. Yan X, Zhang H, Watson J, Schimerlik MI, Deinzer ML. Protein Science 2002;11:2113-2124. [PubMed: 12192067]

30. Chen EI, McClatchy D, Park SK, Yates JR III. Analytical Chemistry (Washington, DC, United States) 2008;80:8694-8701.

31. Chen EI, Cociorva D, Norris JL, Yates JR III. Journal of Proteome Research 2007;6:2529-2538. [PubMed: 17530876]

32. Roos M, Soskic V, Poznanovic S, Godovac-Zimmermann J. J Biol Chem 1998;273:924-931. [PubMed: 9422751]

33. Yoshitomo Hamuro SJC, Molnar Kathleen S, Tuske Steven J, Morrow Jeffrey A. Rapid Communications in Mass Spectrometry 2008;22:1041-1046. [PubMed: 18327892]

34. Papac D, Thornburg K, Bullesbach E, Crouch R, Knapp D. J Biol Chem 1992;267:16889-16894. [PubMed: 1512231] 
35. Pepinsky RB, Zeng C, Wen D, Rayhorn P, Baker DP, Williams KP, Bixler SA, Ambrose CM, Garber EA, Miatkowski K, Taylor FR, Wang EA, Galdes A. J Biol Chem 1998;273:14037-14045. [PubMed: 9593755]

36. Palczewski K, Kumasaka T, Hori T, Behnke CA, Motoshima H, Fox BA, Le Trong I, Teller DC, Okada T, Stenkamp RE, Yamamoto M, Miyano M. Science 2000;289:739-745. [PubMed: 10926528]

37. Dai SY, Burris TP, Dodge JA, Montrose-Rafizadeh C, Wang Y, Pascal BD, Chalmers MJ, Griffin PR. Biochemistry. 2009

38. Dai SY, Chalmers MJ, Bruning J, Bramlett KS, Osborne HE, Montrose-Rafizadeh C, Barr RJ, Wang Y, Wang M, Burris TP, Dodge JA, Griffin PR. Proc Natl Acad Sci U S A 2008;105:7171-7176. [PubMed: 18474858]

39. Avvaru BS, Busby SA, Chalmers MJ, Griffin PR, Venkatakrishnan B, Agbandje-McKenna M, Silverman DN, McKenna R. Biochemistry 2009;48:7365-7372. [PubMed: 19583303]

40. Lauer-Fields JL, Chalmers MJ, Busby SA, Minond D, Griffin PR, Fields GB. J Biol Chem 2009;284:24017-24024. [PubMed: 19574232] 


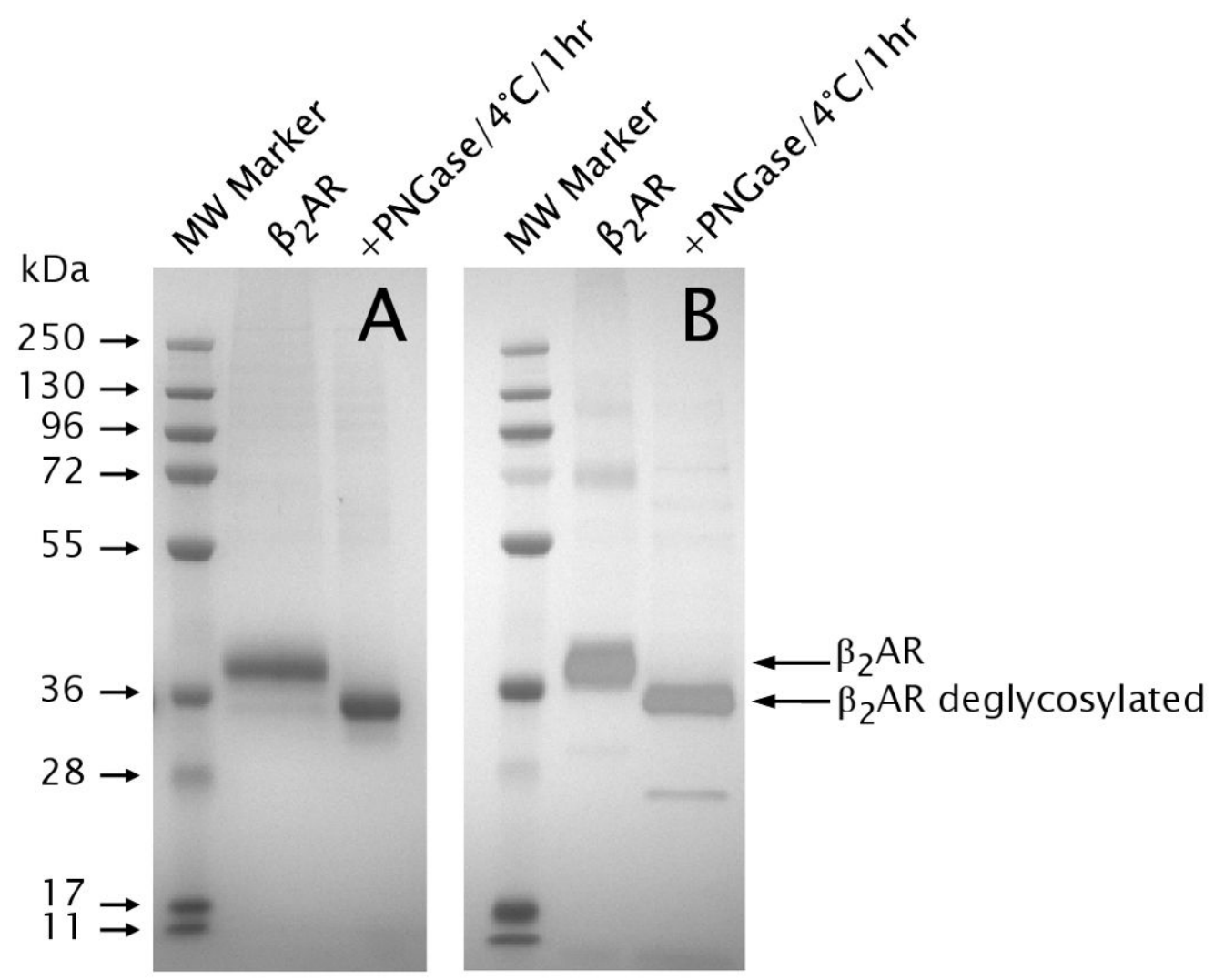

Figure 1.

Western blot analysis of carazolol-bound $\beta_{2} \mathrm{AR} \_460$ after PNGase F incubation at $4{ }^{\circ} \mathrm{C}$ for 1 hour, probed by using anti-FLAG (A), following separation by SDS-PAGE gel 10\% Bis-Tris stained by SimplyBlue Safestain (B). 


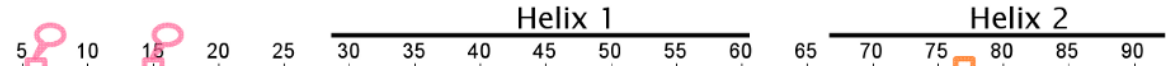

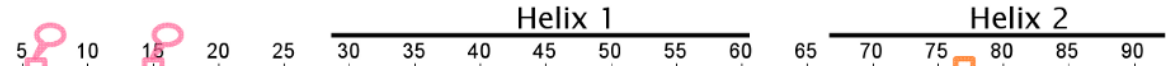
DYKDDDDDAMGQPGNGSAFLLAP NRS HAPDHDVTQQQRDEVWWVGIMGI VMSLI VLAI VFGNVLVI TAI AKFERLQQTVTNYYFI TSLACADLLVMGLAVVPFGAA

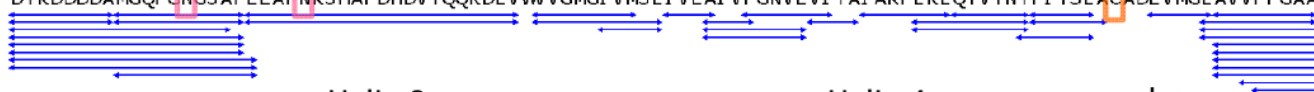
Helix 3

Helix 4

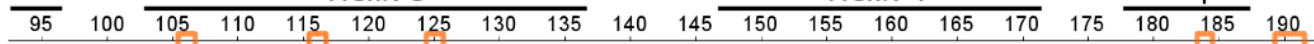

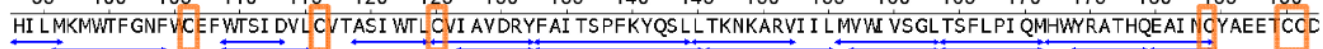

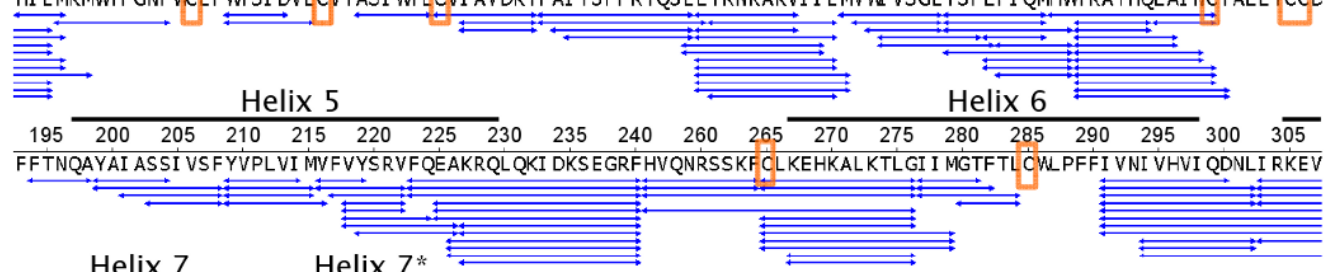

\section{Helix 7} Helix $7 *$

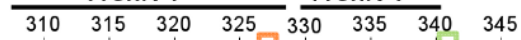

YI LLNWL GYVNSGFNPLI YCRS PDFRI AFQELLCLRRSSLKHHHHHHHHHH

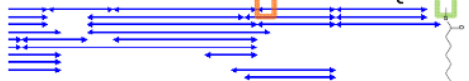

Figure 2.

Peptide sequence map showing the MS/MS and MS verified coverage of carazolol-bound $\beta_{2} \mathrm{AR}$ obtained under experimental conditions used in HDX experiments: $15 \mu \mathrm{M}$ deglycosylated $\beta_{2} \mathrm{AR}$ digested online using the immobilized pepsin column at room temperature $\left(22^{\circ} \mathrm{C}\right)$ and the quench solution containing $0.1 \mathrm{M} \mathrm{NaPi} / \mathrm{HCl}(\mathrm{pH} 2.4) 0.02 \%$ (m/ v) DDM and 10-15 mM TCEP. Pink box dictates sites of N-glycosylation. Orange box indicates a cysteine residue (see Supplemental Table 1). Green box dictates site of protein palmitoylation. 


\section{A) $30 \mathrm{~s}$ \\ B) $300 \mathrm{~s}$ \\ C) $15 \mathrm{hr}$}
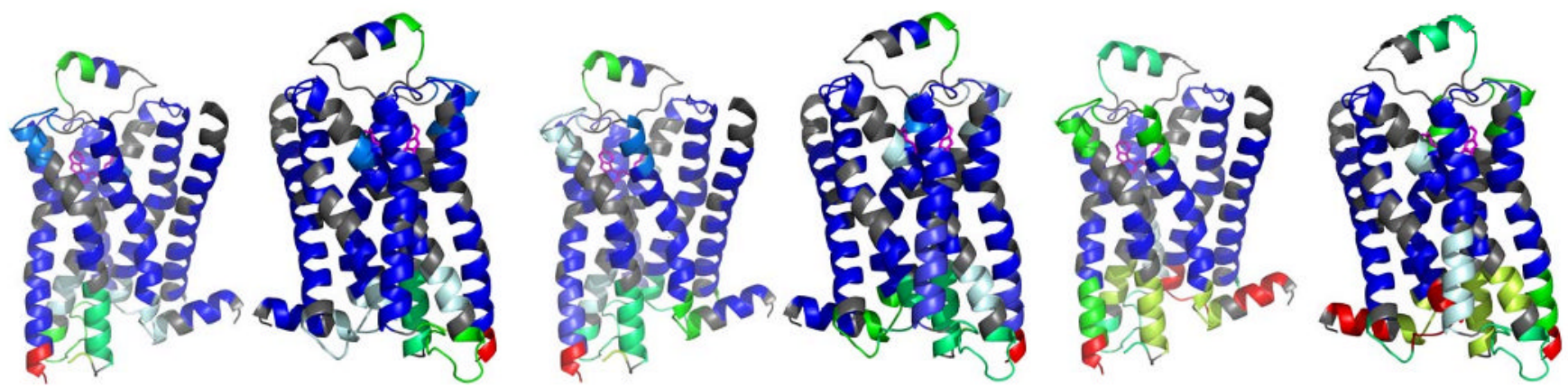

$\% \mathrm{D}$

\begin{tabular}{l|l|l|}
$0-10$ & $10-20$ & $20-30$
\end{tabular}

$30-40 \quad 40-50$

$50-60$

$60-70$

$70-80$

$80-90$

$90-100$

Figure 3.

HDX profile of carazolol-bound $\beta_{2} \mathrm{AR}$ mapped to a model derived from the 3-D crystal structure of $\beta_{2}$ AR T4L (PDB: 2RH1) after exchange time of $30 \mathrm{~s} \mathrm{(A),} 300 \mathrm{~s} \mathrm{(B)}$ and $15 \mathrm{hr}(\mathrm{C})$. Two views are represented for each timepoint. Each pair corresponds to rotation through $180^{\circ}$. The structure model was derived from 2RH1 with removal of T4L amino acids to reflect the construct used for HDX studies. All non-protein molecules were removed with the exception of carazolol. Gray cartoons represent the sequences not presented in the HDX profile. 


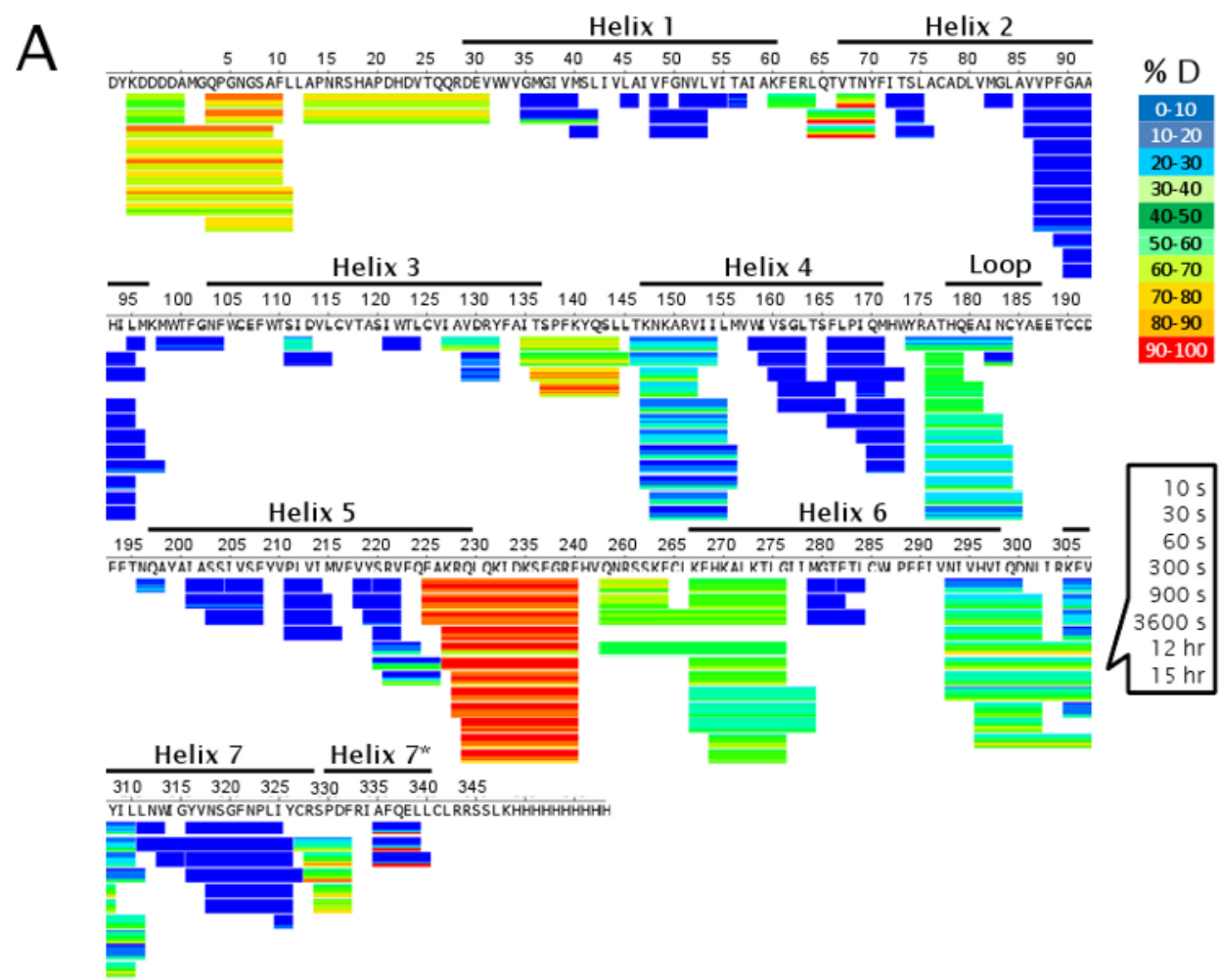

B

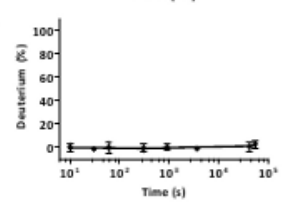

144-154(+2)

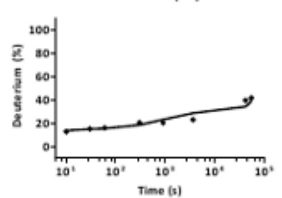

$241-244260-276(* 4)$

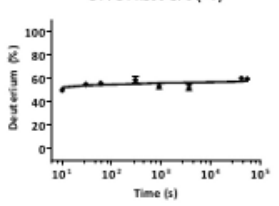

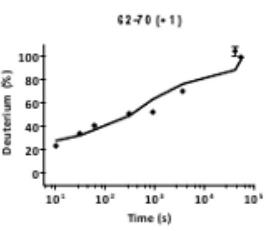

$157-163(\cdot 1)$

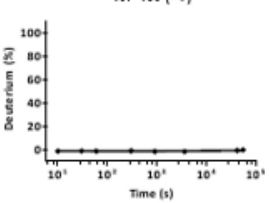

$303.310(-2)$

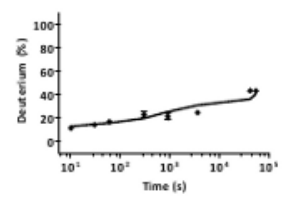

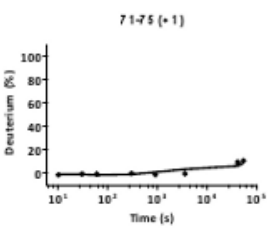

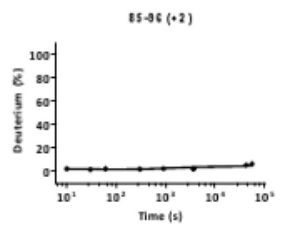

$174-184(+2)$

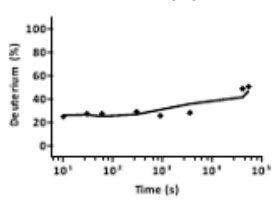

$326-332(\cdot 2)$

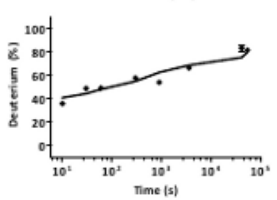

$30-40$

- 60

$0-90$

Figure 4.

HDX profile of deglycosylated $\beta_{2} \mathrm{AR}$ mapped to its sequence after exchange time of $10 \mathrm{~s}, 30$ s, $60 \mathrm{~s}, 300 \mathrm{~s}, 900 \mathrm{~s}, 3600 \mathrm{~s}, 12 \mathrm{~h}$ and $15 \mathrm{~h}$ and discarding the first two amino acid residues at the $\mathrm{N}$-terminus of each peptide (A), and graphs of $\% \mathrm{D}$ as a function of exchange time in log scale for selected peptide ions shown in panel A (B). The error bars in panel B were plotted as the standard deviation of four independent replicates, although in some cases the error bars are too small to be visible. 


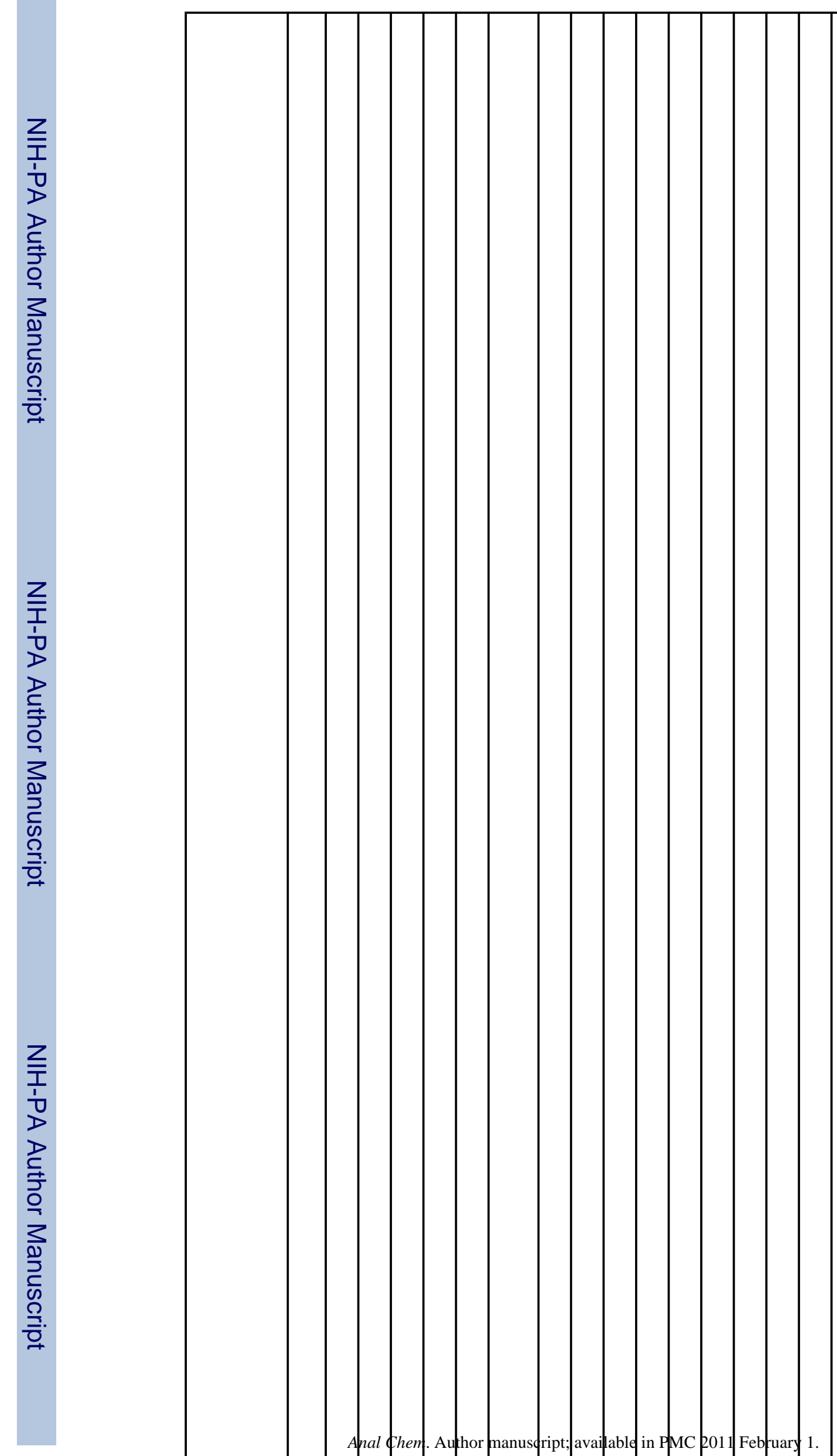




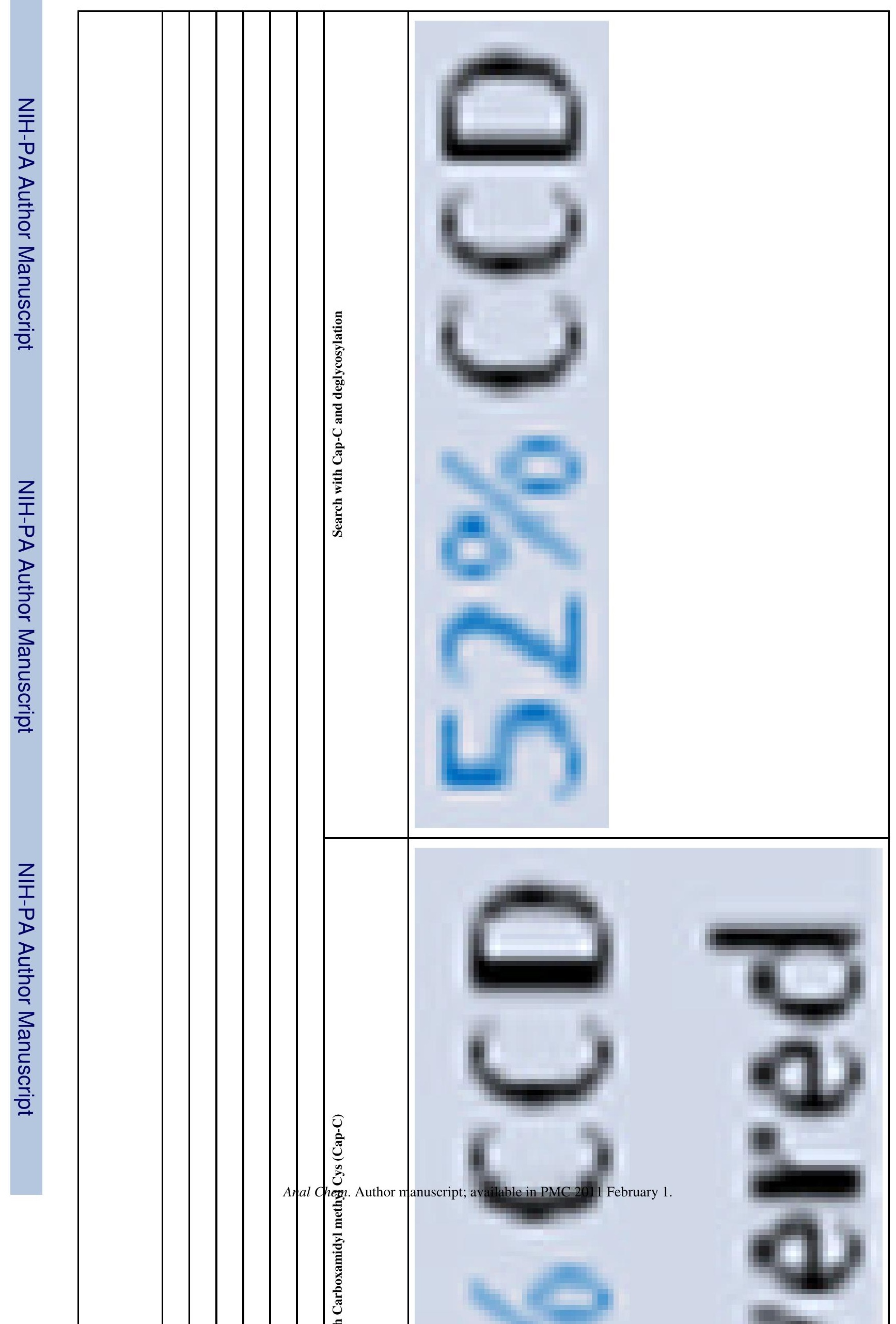



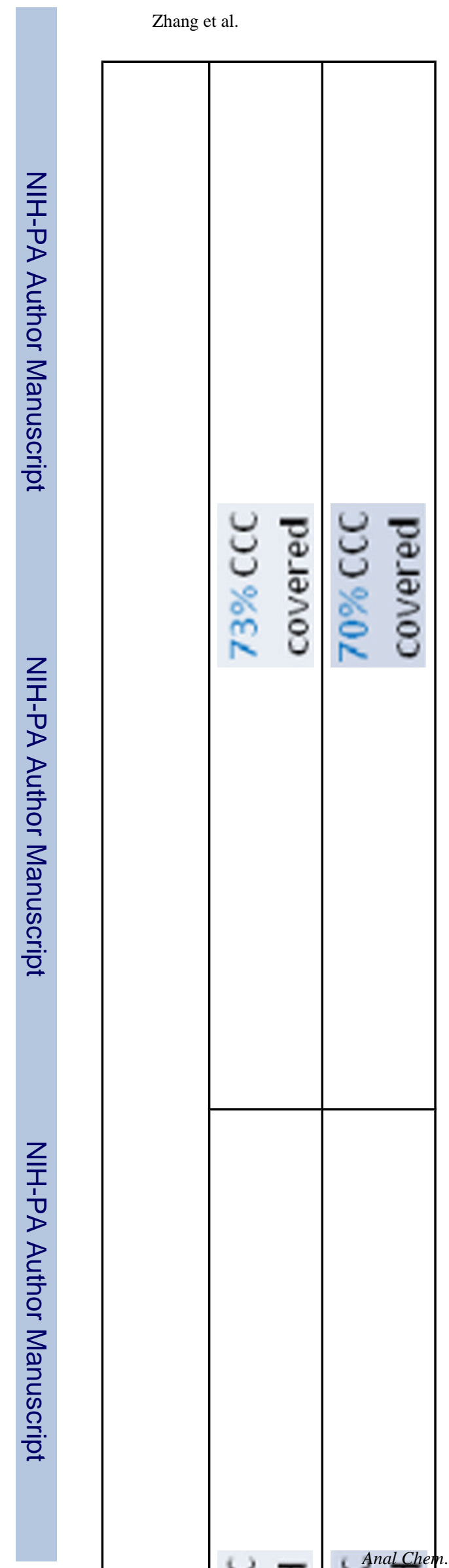